\title{
Microstructure, Magnetic Permeability and Electric Resistivity of High Manganese-Chromium-Nickel Steel ${ }^{*}$
}

\author{
By Hirofumi YOSHIMURA, ** Takaharu SHIMIZU*** \\ and Nao-omi YAMADA***
}

\section{Synopsis}

In order to develop the austenitic steel with the nonmagnetic characteristics, microstructures, mechanical properties, magnetic permeability and electric resistivity of $\mathrm{Mn}-\mathrm{Cr}-\mathrm{Ni}$ steels with much amount of manganese as an austenitizing element have been examined. The results obtained are as follows.

It was found that composition range showing stable austenite phase lays on the higher content side of the line connecting approximately $10 \% \mathrm{Mn}-$ $10 \% \mathrm{Cr}$ and $20 \% \mathrm{Mn}-0 \% \mathrm{Cr}$ in $\mathrm{Mn}-\mathrm{Cr}-1 \% \mathrm{Ni}$ phase diagram. This composition range moved to the line connecting approximately $20 \% \mathrm{Mn}-$ $10 \% \mathrm{Cr}$ and $23 \% \mathrm{Mn}-0 \% \mathrm{Cr}$ in the case of cold-rolled steel plate. High toughness and magnetic permeability $(\mu)$ under $1.01 \sim 1.02$ were obtained in the steel with complete austenite phase. Magnetic permeability markedly increased by small amount of martensite in austenite phase. Therefore, it is necessary that nonmagnetic steel have complete austenite phase. The relationship between electric resistivity $(\rho)$ and alloying elements; manganese, chromium, nickel, silicon in austenite phase, can be written as

$$
\begin{aligned}
\rho= & 1.27[\% \mathrm{Mn}]+0.66[\% \mathrm{Cr}]+1.62[\% \mathrm{Ni}] \\
& +5.90[\% \mathrm{Si}]+36(\mu \Omega-\mathrm{cm})
\end{aligned}
$$

From the above results, $25 \mathrm{Mn}-5 \mathrm{Cr}-1 \mathrm{Ni}$ steel may be selected as an optimum composition from the view points of stable austenite, high toughness, nonmagnetism and suitable electric resistivity.

\section{Introduction}

Austenitic steels not only have excellent corrosion and heat resistance as represented by the 18-8 stainless steel, but also possess good low-temperature toughness characteristic of the austenite phase and are nonmagnetism. The authors ${ }^{1,2)}$ already conducted basic research on the cryogenic applications of $\mathrm{Mn}-\mathrm{Cr}-\mathrm{Ni}$ steels by focusing attention on their good low-temperature toughness and small thermal expansion coefficient, and found the $25 \% \mathrm{Mn}-5 \% \mathrm{Cr}-1 \% \mathrm{Ni}$ steel as grade of the optimum chemical composition for cryogenic service. This steel has a stable austenite phase and thus may be applicable as a nonmagnetic steel.

As austenitic manganese steels are now highlighted as steels to meet a growing demand for nonmagnetic steels to be used, for example, in magnetically levitated transports, ${ }^{3)}$ the authors have investigated on the basis of the previously reported cryogenic application research results various $\mathrm{Mn}-\mathrm{Cr}-\mathrm{Ni}$ steels for their composition range that exhibits the stable austenite phase and for their magnetic permeability and electric resistivity as physical properties that indicate their toughness and nonmagnetism, and studied their applicability as nonmagnetic steels.

\section{Overview of Past Research Results}

Works on the use of $\mathrm{Mn}-\mathrm{Cr}$ austenitic steels for cryogenic service are summarized in the previous reports. $^{1,2)}$ It should be especially noted that high$\mathrm{Mn}-\mathrm{Cr}$ steels have recently been studied by researchers the world over, particularly in the United States and the Soviet Union. ${ }^{4}$ Research on austenitic manganese steels as nonmagnetic steels is mainly concerned with the practical use of already known nonmagnetic steels. Ishida et al.,5) investigated the effects of working and heat treating conditions on the magnetic permeability of the $15 \% \mathrm{Mn}-1.2 \% \mathrm{Ni}$ steel as base composition steel and studied the practical applicability of the steel. Ohno et al., ${ }^{6)}$ conducted research concerning reinforcing bar applications, while Nishimura et al., ${ }^{7)}$ investigated $\mathrm{Mn}-\mathrm{Cr}$ base composition steels with large additions of nickel, molybdenum, vanadium, cobalt and other alloying elements as nonmagnetic tool steels. Nonmagnetic steels must have a microstructurally stable austenite phase. The authors ${ }^{1,2)}$ found the $25 \% \mathrm{Mn}-5 \% \mathrm{Cr}-$ $1 \% \mathrm{Ni}$ steel of optimum chemical composition in this sense and demonstrated that the steel exhibits a stable austenite phase at subzero temperatures down to the liquid-helium temperature and can be used at that temperature. This work can become the basis for research on austenitic steels or nonmagnetic steels. On the basis of these research results, the authors then investigated the effects of manganese, chromium, nickel and other elements on austenitization as well as magnetic permeability and electric resistivity. This paper summarizes the details of that study. Ohtani and $\mathrm{Okada}^{8)}$ subsequently conducted similar investigations on steels with the base composition ranges of 10 to $12 \% \mathrm{Mn}, 0$ to $15 \% \mathrm{Cr}$ and 0.05 to 0.45 $\% \mathrm{C}$.

\section{Experimental Method}

The magnetic permeability $\mu$ varies with the structures of austenite $\gamma$ and martensite $\alpha^{\prime} .^{\dagger}$ Based on the past study results, ${ }^{1,2}$ ) therefore, the test steels in the

\footnotetext{
* Originally published in Tetsu-to-Hagané, 65 (1979), 1435, in Japanese. English version received May 11, 1982. (C) 1983 ISIJ

** Formerly Yawata Works, Nippon Steel Corporation. Now at Hikari Works, Nippon Steel Corporation, Shimada, Hikari 743.

*** Yawata Works, Nippon Steel Corporation, Edamitsu, Yawatahigashi-ku, Kitakyushu 805.

**** Technical Development Department, Nippon Steel Corporation, Otemachi, Chiyoda-ku, Tokyo 100.

$\uparrow \quad$ For the sake of brevity, magnetic permeability, electric resistivity, austenite, ferrite and martensite are sometimes signified hereinafter by $\mu, \rho, \gamma, \alpha$ and $\alpha^{\prime}$, respectively. The $\varepsilon$ phase in the $\gamma$ phase in difficult to distinguish from streaks due to stacking faults or twin boundaries in optical microstructures. As a result, it is treated as a kind of stacking fault in the $\gamma$ phase and is described as the $\gamma$ phase even if it exists.
} 
present work had the manganese, chromium, nickel and silicon contents widely varied so as to clarify the composition boundary of the nonmagnetic region or $\gamma$ region. The composition ranges studied are given in Table 1.

10 to $20 \mathrm{~kg}$ of each test steel were melted in an argon atmosphere, cast into ingots 10 to $20 \mathrm{~kg}$ in weight, reheated to $1473 \mathrm{~K}$, rough rolled, finish rolled at $1193 \mathrm{~K}$ into $13-\mathrm{mm}$ thick plates, and cooled in air. To investigate how cold working would change the stable $\gamma$ region in terms of composition, some of these test steel plates were additionally cold rolled by $5,12.5$ and $25 \%$, respectively.

From these test steel plates of different chemical compositions were prepared specimens for chemical analysis, specimens for optical microscopy, JIS No. 4 tensile test specimens for determining tensile strength at ambient temperature, JIS No. 4 2-mm V-notch Charpy impact test specimens for determining impact strength, $9-\mathrm{mm}$ diameter by $120-\mathrm{mm}$ long round specimens for measuring magnetic permeability, and 5-mm diameter by $120-\mathrm{mm}$ long round specimens for measuring electric resistivity.

Optical microstructures were observed at the magnification of 200X. Tensile tests determined $0.2 \%$ proof strength (PS) and tensile strength (TS), and impact tests were conducted at an ambient temperature of $293 \mathrm{~K}$ and liquid-nitrogen temperature of $77 \mathrm{~K}$. The amount of $\alpha^{\prime}$ in each specimen for optical microscopy was measured with a ferrite indicator.* Some of the amounts of $\alpha^{\prime}$ thus determined were verified by the X-ray diffraction technique. The magnetic permeability $\mu$ was measured with a bal-

Table 1. Ghemical composition range of experimental steels. (\%)

\begin{tabular}{c|rl}
\hline (1) $\begin{array}{c}\text { For the influence } \\
\text { alloying element }\end{array}$ & (2) Other element \\
\hline $\mathrm{Mn}: 5.0 \sim 26.0$ & $\mathrm{C}: 0.09 \sim 0.16$ \\
$\mathrm{Cr}: 0 \sim 15.0$ & $\mathrm{P}: 0.002 \sim 0.046$ \\
$\mathrm{Ni}: 0 \sim 6.0$ & $\mathrm{~S}: 0.002 \sim 0.013$ \\
$\mathrm{Si}: 0.1 \sim 5.2$ & $\mathrm{Nb}:$ Tr. $\sim 0.17$ \\
& $\mathrm{Al}: 0.008 \sim 0.31$ \\
& $\mathrm{~N}: 0.049 \sim 0.086$ \\
\hline
\end{tabular}

listic galvanometer according to ASTM A342-64. The electric resistivity $\rho$ was measured with a potential difference gauge length of $50 \mathrm{~mm}$ on the abovementioned specimens, using a standard resistance of $0.01 \Omega$.

\section{Experimental Results and Discussion}

\section{Microstructure and Mechanical Properties}

Figure 1 shows changes in microstructure (hereinafter referred to as the Mn-Cr constitution diagram) and mechanical properties when the nickel content is fixed at $1 \%$ while the manganese and chromium contents are varied. The analyzed chemical compositions of typical test steels are given in Table 2 .

The Mn-Cr constitution diagram of Fig. 1 was derived from the microstructures observed with an optical microscope and the amounts of $\alpha^{\prime}$ measured with the ferrite indicator, and is almost the same as that presented in the previous report. ${ }^{1)}$ Microstructures of representative test steels are shown in Photo. 1. Steel exhibits the $\gamma$ phase at ambient temperature when the manganese and chromium contents are

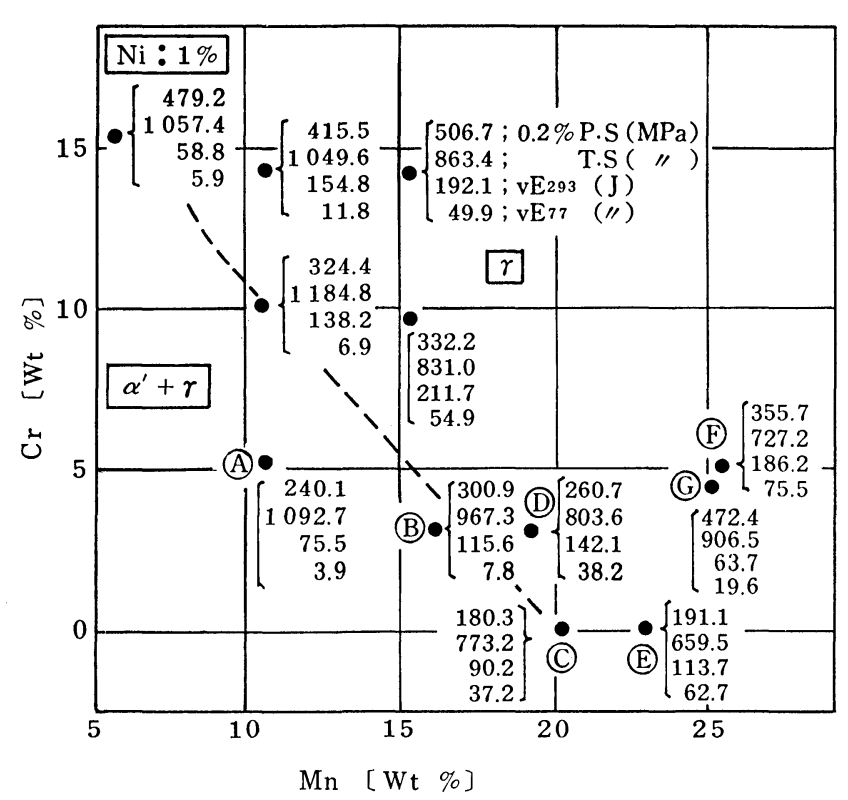

Fig. 1. Strength and toughness of $\mathrm{Mn}-\mathrm{Cr}-\mathrm{Ni}$ steel.

Table 2. Typical example of chemical composition in experimental steels.

\begin{tabular}{|c|c|c|c|c|c|c|c|c|c|c|}
\hline Marks & Alloying system & $\mathrm{C}$ & $\mathrm{Si}$ & $\mathrm{Mn}$ & $\mathbf{P}$ & $\mathrm{S}$ & $\mathrm{Cr}$ & $\mathrm{Ni}$ & $\mathrm{Al}$ & $\mathrm{N}$ \\
\hline A & $11 \mathrm{Mn}-5 \mathrm{Cr}-1 \mathrm{Ni}$ & 0.14 & 0.31 & 10.78 & 0.005 & 0.011 & 5.13 & 0.96 & 0.03 & 0.059 \\
\hline B & $16 \mathrm{Mn}-3 \mathrm{Cr}-1 \mathrm{Ni}$ & 0.15 & 0.31 & 16.30 & 0.026 & 0.008 & 2.99 & 1.09 & 0.03 & 0.072 \\
\hline G & $20 \mathrm{Mn}-0 \mathrm{Cr}-1 \mathrm{Ni}$ & 0.15 & 0.31 & 20.40 & 0.002 & 0.008 & - & 0.82 & 0.03 & 0.035 \\
\hline $\mathrm{D}$ & $20 \mathrm{Mn}-3 \mathrm{Cr}-1 \mathrm{Ni}$ & 0.13 & 0.31 & 19.60 & 0.026 & 0.010 & 2.90 & 1.09 & 0.04 & 0.013 \\
\hline $\mathrm{E}$ & $23 \mathrm{Mn}-0 \mathrm{Cr}-1 \mathrm{Ni}$ & 0.14 & 0.30 & 23.10 & 0.002 & 0.009 & - & 0.98 & 0.03 & 0.028 \\
\hline $\mathrm{F}$ & $25 \mathrm{Mn}-5 \mathrm{Cr}-1 \mathrm{Ni}$ & 0.15 & 0.40 & 25.50 & 0.046 & 0.010 & 5.00 & 1.10 & $\begin{array}{r}0.02 \\
\mathrm{Nb} 0.09\end{array}$ & 0.086 \\
\hline G & $\begin{array}{l}25 \mathrm{Mn}-5 \mathrm{Cr}-1 \mathrm{Ni}- \\
5 \mathrm{Si}\end{array}$ & 0.16 & 5.13 & 25.00 & 0.019 & 0.009 & 4.73 & 1.08 & $\begin{array}{r}0.03 \\
\mathrm{Nb} 0.10\end{array}$ & 0.079 \\
\hline
\end{tabular}

\footnotetext{
* An instrument that determines the amount of $\alpha$ or $\alpha^{\prime}$ by utilizing the characteristic that steel becomes a ferromagnetic material when the $\alpha$ or $\alpha^{\prime}$ phase is formed in the $\gamma$ phase. The ferrite indicator used in the present experiments was made by Helmut Fischer GmbH of F.R. Germany.
} 


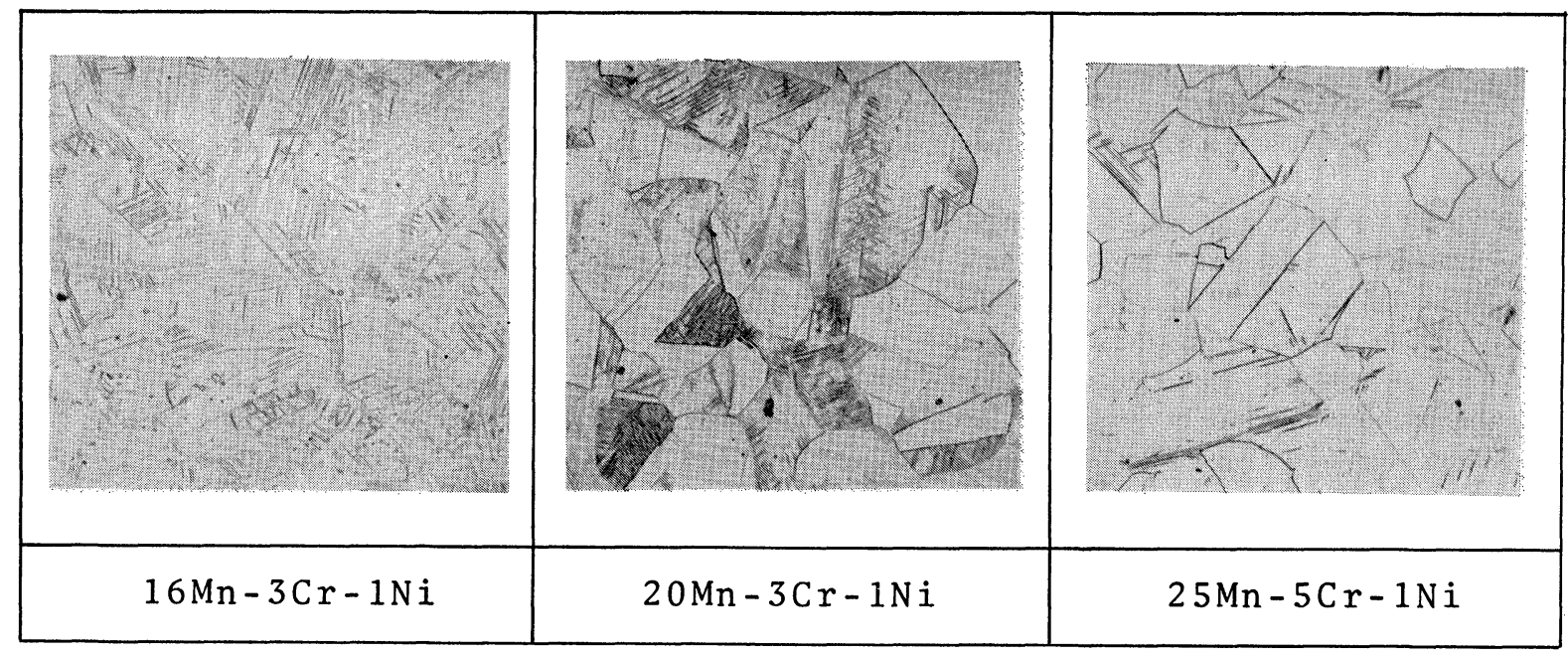

Photo. 1. Microstructure of Mn-Cr-Ni steel. $(\times 200)$

above the boundary line (dotted line) that connects $10 \% \mathrm{Mn}-10 \% \mathrm{Cr}$ and $20 \% \mathrm{Mn}-0 \% \mathrm{Cr}$ in the constitution diagram.

When steel has manganese and chromium contents below the boundary line (for example, steel A of the $11 \% \mathrm{Mn}-5 \% \mathrm{Cr}$ system), it shows a high tensile strength. As the manganese content increases or the steel enters the $\gamma$ phase region, the tensile strength decreases. The proof strength remains unchanged or increases slightly. Virtually the same tendencies are observed with chromium as well. As the chromium content increases in the $\gamma$ phase region, both tensile strength and proof strength increase slightly. This is probably due to the solid solution hardening of chromium. The effect of chromium content in excess of $15 \%$ is not investigated here, because it was made clear by Binder et al., ${ }^{9}{ }^{9}$ that the $\alpha^{\prime}$ phase appears when the chromium content exceeds $15 \%$.

The test steels $\mathrm{F}$ and $\mathrm{G}$ in the $\gamma$ phase region are $25 \% \mathrm{Mn}-5 \% \mathrm{Cr}-1 \% \mathrm{Ni}$ steels with different silicon contents. The addition of $5 \%$ silicon increases the $0.2 \%$ proof strength and tensile strength by about 100 and $150 \mathrm{MPa}$, respectively. With these high manganese, chromium and nickel contents, the $r$ phase is so stable than no $\alpha$ or $\alpha^{\prime}$ phase is detected even when silicon, a ferrite former, is added $5 \%$.

Charpy impact test values $\mathrm{v} E_{293}$ and $\mathrm{v} E_{77}$ at ambient temperature and liquid-nitrogen temperature are examined as toughness properties. The $\mathrm{v} E_{293}$ value is considerably high even if $\alpha^{\prime}$ is present in some amount, but the $v E_{77}$ value drops under the increasing influence of $\alpha^{\prime}$. The relation of toughness with steel composition is opposite to that of strength with steel composition. This means that steels of optimum chemical composition for toughness must be particularly within the stable $\gamma$ phase region. The $25 \%$ $\mathrm{Mn}-5 \% \mathrm{Cr}-1 \% \mathrm{Ni}$ steel for cryogenic service reported previously, for example, shows very good toughness.

\section{Microstructure and Magnetic Permeability $\mu$}

The relationship between the Mn-Cr constitution diagram and magnetic permeability $\mu$ is shown in Fig. 2. The magnetic permeability $\mu$ is below 1.01

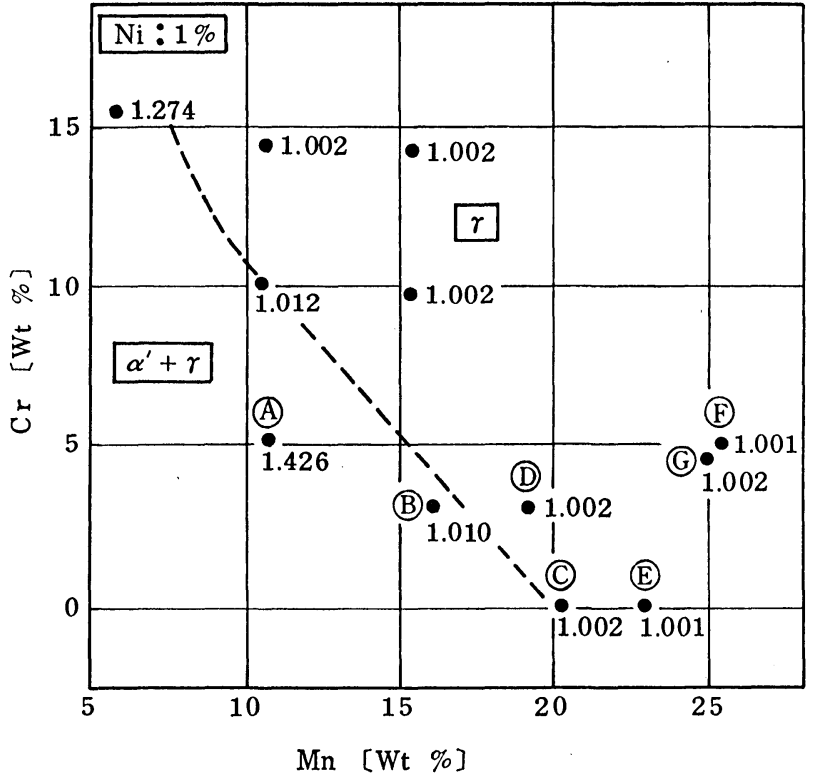

Fig. 2. Magnetic permeability of $\mathrm{Mn}-\mathrm{Cr}-\mathrm{Ni}$ steel.

to 1.02 when the manganese and chromium contents are above the boundary line (dotted line) that connects $10 \% \mathrm{Mn}-10 \% \mathrm{Cr}$ and $20 \% \mathrm{Mn}-0 \% \mathrm{Cr}$ and indicates the $\gamma$ phase. As $\alpha^{\prime}$ appears in the region below the boundary line, the magnetic permeability $\mu$ increases. The relationship between the magnetic permeability $\mu$ and the amount of $\alpha^{\prime}$ may be plotted as shown in Fig. 3. The magnetic permeability $\mu$ sharply increases even when the amount of $\alpha^{\prime}$ is extremely small. As evident from these results, nonmagnetic steels must have an extremely stable $\gamma$ phase free of any $\alpha^{\prime}$ phase.

When nonmagnetic steels are put to practical use, they are generally cold worked. Accordingly, the effect of working on the amount of $\alpha^{\prime}$ (that is, $\mu$ ) was investigated. Working was cold rolling and the degree of working was denoted by the ratio of reduction. The investigated results are shown in Fig. 4.

When the as-hot-rolled plate is cold rolled $5 \%$, the stable $\gamma$ phase region (whose boundary is indicated by a dotted line) shifts toward about $3 \%$ higher 
manganese and chromium contents. The reduction of $12.5 \%$ moves the stable $\gamma$ phase region toward still higher manganese and chromium contents. When the as-hot-rolled plate is cold rolled $25 \%$, the stable $\gamma$ region does not shift to a large degree. This shift of the stable $\gamma$ region toward higher manganese and chromium contents by cold rolling indicates that the stress-induced martensite transformation point $M d$ is present within the range bounded by the $0 \%$ and $25 \%$ cold reduction lines in the $\mathrm{Mn}-\mathrm{Cr}$ constitution diagram. According to these results, the manganese and chromium contents must be above the line that connects about $20 \% \mathrm{Mn}-10 \% \mathrm{Cr}$ and about $23 \% \mathrm{Mn}-$ $0 \% \mathrm{Cr}$ if the stable $\gamma$ phase is to be obtained despite heavy working. The previously reported $25 \% \mathrm{Mn}-$ $5 \% \mathrm{Gr}-1 \% \mathrm{Ni}$ steel $^{1,2)}$ that shows a stable $\gamma$ phase and high toughness in cryogenic service in this composi-

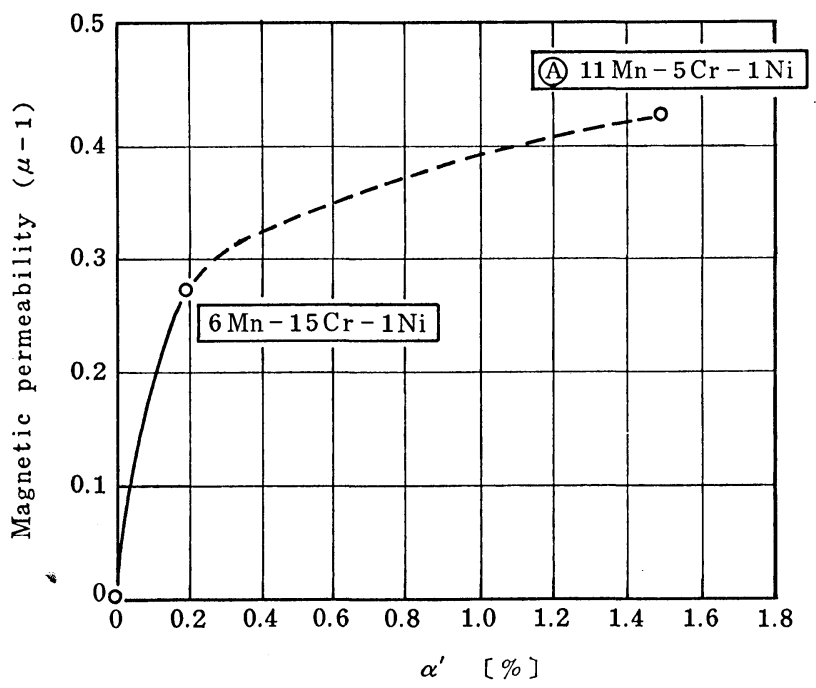

Fig. 3. Relation between magnetic permeability and amount of martensite $\left(\alpha^{\prime}\right)$ in austenite of $\mathrm{Mn}-\mathrm{Cr}$ Ni steel. tion region.

\section{Composition and Electric Resistivity $\rho$}

The electric resistivity $\rho$ of the test steels was measured and the effects of the alloying elements manganese, chromium, nickel and silicon were investigated. The results are shown in Figs. 5 to 8 .

The effect of manganese content is discussed first (Fig. 5). When the $5 \% \mathrm{Cr}-1 \% \mathrm{Ni}$ steel has a manganese content in excess of about $19 \%$ (region that indicates a complete $\gamma$ phase), $\rho$ increases at a slope of $1.48 \mu \Omega-\mathrm{cm} / \%$ (the unit of slope is omitted hereinafter) as the manganese content increases. In the low-manganese region ( $12 \%$ and $16 \% \mathrm{Mn}), \rho$ somewhat deviates from this slope as indicated by $\delta$ in the diagram. This is probably because some $\alpha^{\prime}$ is formed. Since there must be a complete $\gamma$ phase when nonmagnetic steels are considered as mentioned earlier, the results are arranged here by the $\gamma$ phase region. When the electric resistivity $\rho$ of the $25 \%$ $\mathrm{Mn}-5 \% \mathrm{Cr}-1 \% \mathrm{Ni}$ steel that is developed for cryogenic service and found optimum for nonmagnetic application according to the magnetic permeability measurements described above is measured, it is about $73 \mu \Omega-\mathrm{cm}$ and is practically the same as that of the 18-8 stainless steel. The effect of manganese on the electric resistivity $\rho$ of the $5 \% \mathrm{Cr}-5 \% \mathrm{Ni}$ base composition steel changes along the slope of 1.06. Although the former $5 \% \mathrm{Cr}-1 \% \mathrm{Ni}$ steel and latter 5\% $\mathrm{Cr}-5 \% \mathrm{Ni}$ steel differ in base composition, their average slope is 1.27 and may be considered as the effect of manganese on $\rho$.

The effects of chromium, nickel and silicon contents on $\rho$ are similar to that of manganese (Figs. 6 to 8). The average slope of each element is 0.66 for chromium, 1.62 for nickel and 5.90 for silicon, with silicon exerting the largest effect on $\rho$.

The effect of these alloying elements on $\rho$ resembles

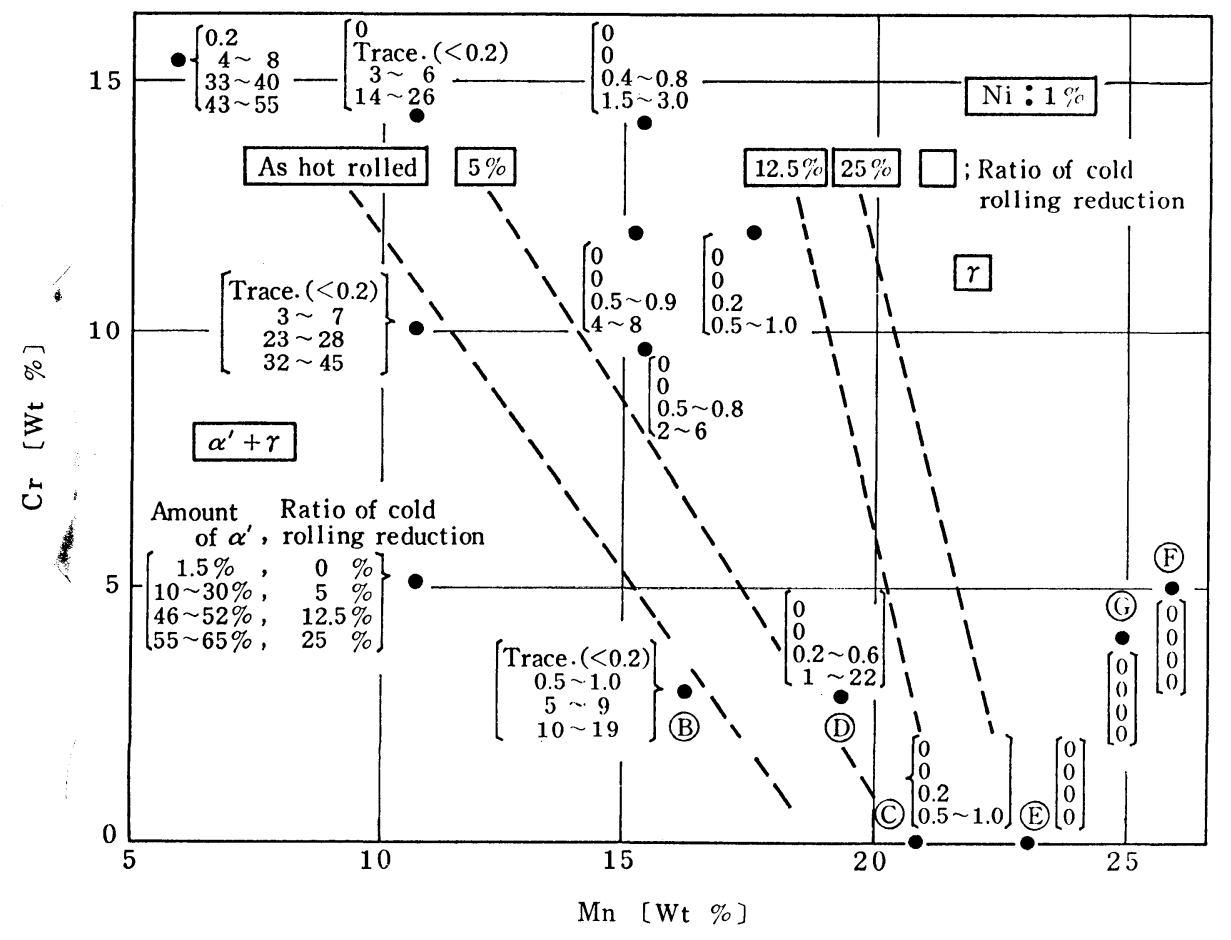

Fig. 4.

Relation between amount of martensite $\left[\alpha^{\prime}\right]$ and ratio of cold rolling reduction in $\mathrm{Mn}-$ $\mathrm{Cr}-\mathrm{Ni}$ steel. 


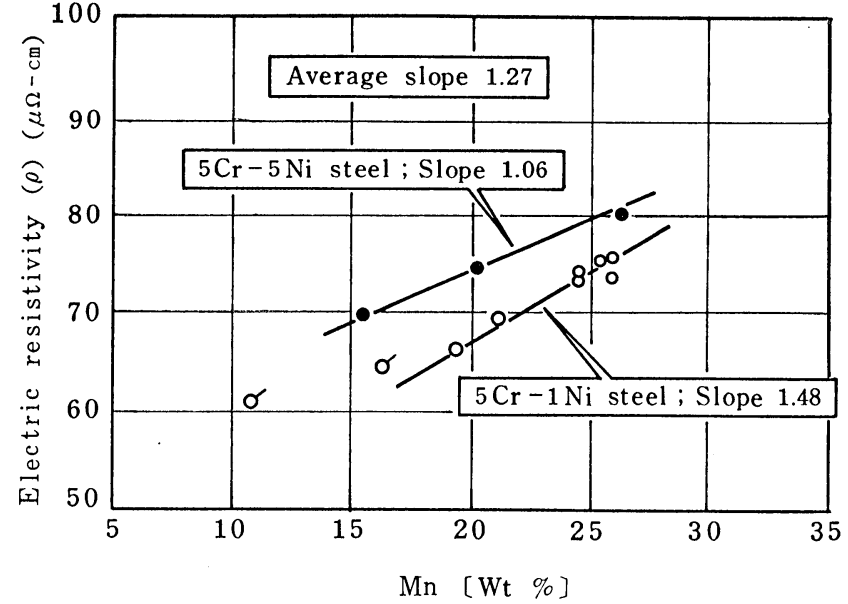

Mark $\delta$ : plot of austenite $(\gamma)+$ martensite $\left(\alpha^{\prime}\right)$ mixed phase

Fig. 5. Influence of manganese content on electric resistivity in $\mathrm{Mn}-\mathrm{Cr}-\mathrm{Ni}$ steel.

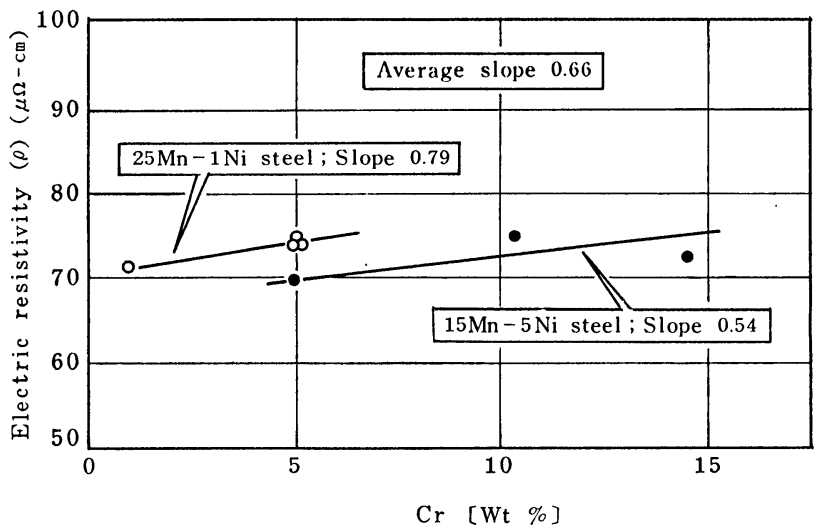

Fig. 6. Influence of chromium content on electric resistivity in $\mathrm{Mn}-\mathrm{Cr}-\mathrm{Ni}$ steel.

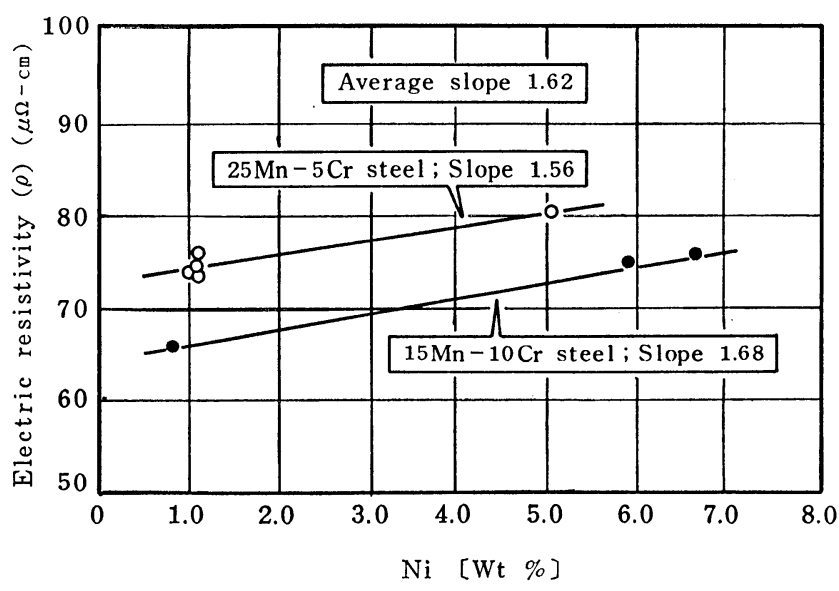

Fig. 7. Influence of nickel content on electric resistivity in $\mathrm{Mn}-\mathrm{Cr}-\mathrm{Ni}$ steel.

their effect on iron ( $\alpha$ phase) $)^{10}$ but is smaller in degree. This may be attributed to the difference in crystal structure between the $\gamma$ phase and $\alpha$ phase.

As the alloying elements increase in content, $\rho$ also increases in magnitude, probably because the periodicity of atoms is disturbed and free electrons are scattered in the same way as free electrons are scattered as metal temperature rises, for example. The

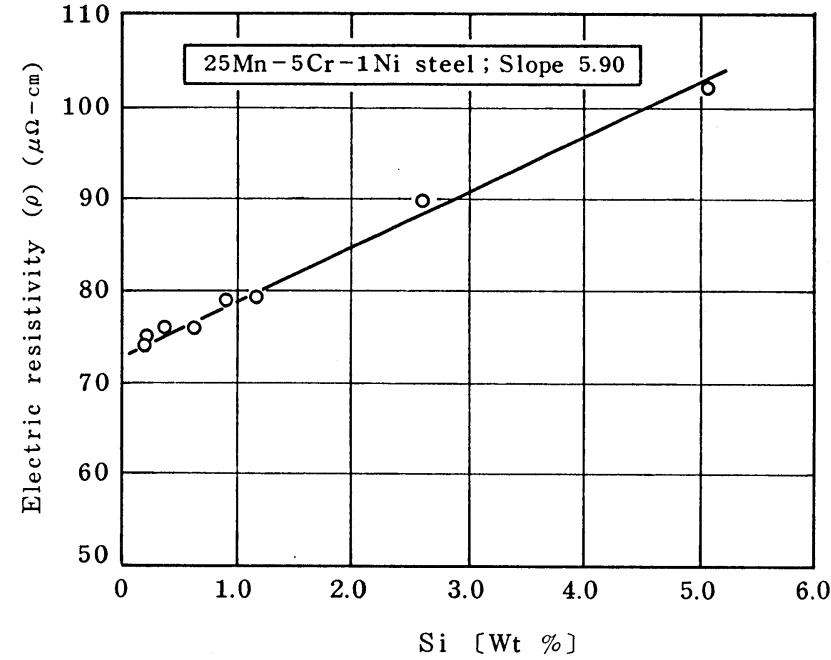

Fig. 8. Influence of silicon content on electric resistivity in $\mathrm{Mn}-\mathrm{Cr}-\mathrm{Ni}$ steel.

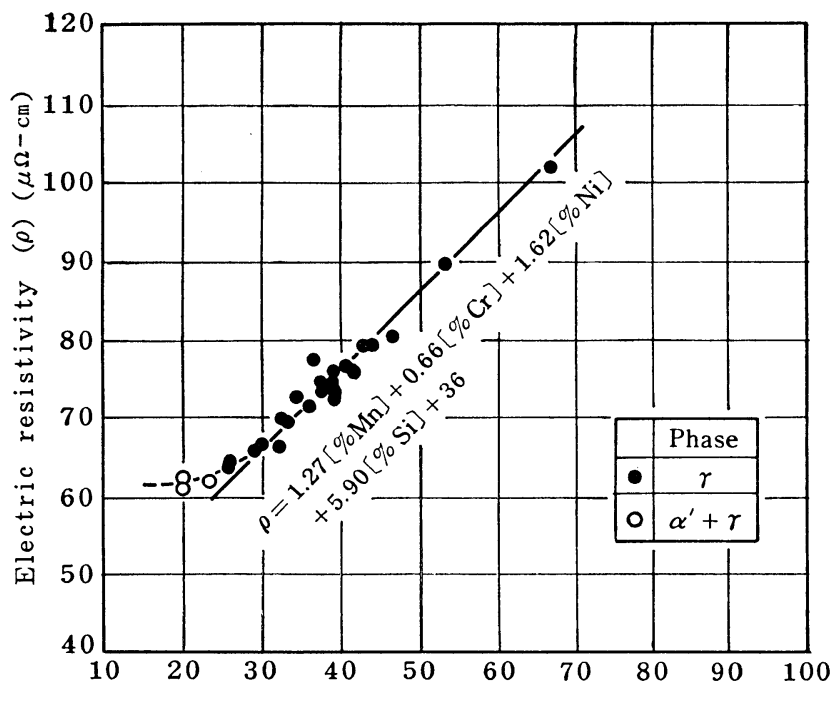

$1.27[\% \mathrm{Mn}]+0.66[\% \mathrm{Cr}]+1.62[\% \mathrm{Ni}]+5.90[\% \mathrm{Si}]$

Fig. 9. Relation between electric resistivity and alloying elements in $\mathrm{Mn}-\mathrm{Cr}-\mathrm{Ni}$ steel.

reason for the difference in the degree of effect of the respective alloying elements is not clear. Within the composition ranges studied by the present work, silicon most greatly affects $\rho$. This appears related in some way to the fact that silicon has the smallest atomic weight and specific gravity among the four elements.

An empirical formula was derived for the effect of the four elements on $\rho$ within the composition ranges given in Table 1. The calculated results are shown in Fig. 9. The electric resistivity $\rho$ is given by

$$
\begin{aligned}
\rho= & 1.27[\% \mathrm{Mn}]+0.66[\% \mathrm{Cr}]+1.62[\% \mathrm{Ni}] \\
& +5.90[\% \mathrm{Si}]+36(\mu \Omega-\mathrm{cm})
\end{aligned}
$$

When the empirical formula is applied to the 18-8 stainless steel, for example, the abscissa of Fig. 9 becomes about 33 and $\rho$ becomes $72 \mu \Omega$-cm. As evident from this example, the empirical formula has a considerable degree of applicability to austenitic steels. 
When the $\alpha^{\prime}$ phase appears, $\rho$ deviates from the empirical formula as shown by open circles in Fig. 9.

\section{Summary}

Since high-Mn-Cr-Ni austenitic steels have the possibility of being used for cryogenic service as well as for nonmagnetic and many other applications, the authors have investigated the microstructure, mechanical properties, magnetic permeability and electric resistivity of the $25 \% \mathrm{Mn}-5 \% \mathrm{Cr}-1 \% \mathrm{Ni}$ base composition steel selected as the optimum one for cryogenic service and other grades with varying manganese, chromium, nickel and silicon contents. The findings obtained may be summarized as follows:

(1) To obtain the $\gamma$ phase at ambient temperature, the manganese and chromium contents must be above the line that connects $10 \% \mathrm{Mn}-10 \% \mathrm{Cr}$ and $20 \% \mathrm{Mn}-0 \% \mathrm{Cr}$ in the $\mathrm{Mn}-\mathrm{Cr}$ constitution diagram with the base nickel content of $1 \%$. In the region of lower manganese and chromium contents, the $\alpha^{\prime}$ phase forms to increase strength but to decrease toughness.

(2) In the above $\gamma$ phase region, $\mu$ is under 1.01 to 1.02. As the $\alpha^{\prime}$ phase appears, $\mu$ sharply increases in magnitude. Steels to be used for nonmagnetic applications, therefore, must have the stable $\gamma$ phase.

(3) When the steel that exhibits the $\gamma$ phase at ambient temperature is cold worked, the $\alpha^{\prime}$ phase appears. If the steel is to retain the stable $\gamma$ phase under heavy working (cold reduction of 12 to $25 \%$ ), its manganese and chromium contents must be above the line that connects $20 \% \mathrm{Mn}-10 \% \mathrm{Cr}$ and $23 \% \mathrm{Mn}-$ $0 \% \mathrm{Cr}$ in the $\mathrm{Mn}-\mathrm{Cr}$ constitution diagram.

(4) The effects of the alloying elements manganese, chromium, nickel and silicon on the electric resistivity $\rho$ of the steels that exhibit the $\gamma$ phase have been investigated. As a result, the following empirical formula has been obtained:

$$
\begin{aligned}
\rho= & 1.27[\% \mathrm{Mn}]+0.66[\% \mathrm{Cr}]+1.62[\% \mathrm{Ni}] \\
& +5.90[\% \mathrm{Si}]+36(\mu \Omega-\mathrm{cm})
\end{aligned}
$$

The electric resistivity $\rho$ increases in magnitude as the content of each alloying element increases. Of the four elements, silicon most greatly affects $\rho$.

(5) When the above results are taken into account together with the results described in the previous reports, ${ }^{1,2)}$ the $25 \% \mathrm{Mn}-5 \% \mathrm{Cr}-1 \% \mathrm{Ni}$ steel that shows the stable $\gamma$ phase and has good low-temperature toughness, stable nonmagnetism and electric resistivity comparable to that of the 18-8 stainless steel is considered as optimum nonmagnetic steel.

\section{Acknowledgements}

The authors wish to thank Messrs. Tadashi Nishi and Hiroshi Yada, Process Technology R \& D Laboratories, Nippon Steel Corp., for their advice and cooperation in the experiments of the present work.

\section{REFERENGES}

1) H. Yoshimura, N. Yamada, H. Yada, H. Honma and T. Ito: Trans. ISIJ, 16 (1976), 98.

2) H. Yoshimura, T. Shimizu, H. Yada and K. Kitajima: Trans. ISIJ, 20 (1980), 187.

3) Y. Kyotani: Chemical Economy \& Engineering Review, 6 (1974), No. 12, 22.

4) J. M. Morris, Jr., S. K. Hwang, K. A. Yushchenko, V. I. Belotzerkovetz and O. G. Kvansnevskii: Advances in Cryogenic Engineering, 24 (1978), 91; Proc. the 2nd Int'l Cryogenics Materials Conf., Colorado, August 1977.

5) T. Kato, M. Fujikura, S. Yakagi and M. Ishida: DenkiSeiko (Electric Furnace Steel), 49 (1978), 90.

6) T. Ohno, N. Kato, M. Takahashi and K. Aihara: Sumitomo Metals, 30 (1978), No. 2, 54.

7) T. Nishimura, H. Kikuchi and M. Imamura: Denki-Seiko (Electric Furnace Steel), 48 (1977), 65.

8) Y. Ohtani and Y. Okada: Tetsu-to-Hagané, 64 (1978), S859.

9) R. Franks, W. O. Binder and J. Thompson: Trans. ASM, 47 (1955), 231.

10) R. M. Bozorth: Ferromagnetism, (1951), 40. 